\title{
Rolling Blackout Is Required for Synaptic Vesicle Exocytosis
}

\author{
Fu-De Huang, Elvin Woodruff, Ralf Mohrmann, and Kendal Broadie \\ Department of Biological Sciences, Vanderbilt Kennedy Center for Research on Human Development, Vanderbilt Brain Institute, Vanderbilt University, \\ Nashville, Tennessee 37235-1634
}

\begin{abstract}
Rolling blackout (RBO) is a putative transmembrane lipase required for phospholipase C-dependent phosphatidylinositol 4,5-bisphosphate-diacylglycerol signaling in Drosophila neurons. Conditional temperature-sensitive (TS) rbo mutants display complete, reversible paralysis within minutes, demonstrating that RBO is acutely required for movement. RBO protein is localized predominantly in presynaptic boutons at neuromuscular junction (NMJ) synapses and throughout central synaptic neuropil, and rbo TS mutants display a complete, reversible block of both central and peripheral synaptic transmission within minutes. This phenotype appears limited to adults, because larval NMJs do not manifest the acute blockade. Electron microscopy of adult rbo TS mutant boutons reveals an increase in total synaptic vesicle (SV) content, with a concomitant shrinkage of presynaptic bouton size and an accumulation of docked SVs at presynaptic active zones within minutes. Genetic tests reveal a synergistic interaction between rbo and syntaxin1A TS mutants, suggesting that RBO is required in the mechanism of $N$-ethylmaleimide-sensitive factor attachment protein receptor (SNARE)-mediated SV exocytosis, or in a parallel pathway necessary for SV fusion. The rbo TS mutation does not detectably alter SNARE complex assembly, suggesting a downstream requirement in SV fusion. We conclude that RBO plays an essential role in neurotransmitter release, downstream of SV docking, likely mediating SV fusion.
\end{abstract}

Key words: Drosophila; temperature-sensitive paralysis; giant fiber circuit; neurotransmission; synapse; membrane lipase; syntaxin

\section{Introduction}

Drosophila temperature-sensitive (TS) paralytic mutants have long proven to be critical tools for the discovery and elucidation of the molecular mechanisms of neurotransmission. These mutants have identified numerous classes of proteins acutely required in neuronal signaling, most prominently including ion channels [e.g., paralytic, $\mathrm{Na}^{+}$channel subunit (Loughney et al., 1989) and cacophony, $\mathrm{Ca}^{2+}$ channel subunit (Kawasaki et al., 2000)] and components of the synaptic vesicle (SV) cycle [e.g., shibire, a dynamin GTPase (van der Bliek and Meyerowitz, 1991) and comatose, $N$-ethylmaleimide-sensitive fusion (NSF) factor (Ordway et al., 1994)], among others (Littleton et al., 1998; Rao et al., 2001). Such conditional mutants are particularly valuable because they provide the opportunity to study neurotransmission when gene product function is acutely removed and thus bypass any requirement in cell viability or development. Perhaps the most seminal example of this approach has been the isolation and characterization of the shibire TS mutant, which first revealed the essential requirement of dynamin GTPase in SV endocytosis (Koenig et al., 1983; Koenig and Ikeda, 1996; Kidokoro et al.,

Received Sept. 6, 2005; revised Jan. 12, 2006; accepted Jan. 17, 2006

This work was supported entirely by National Institutes of Health Grant GM54544 to K.B. We are particularly grateful to Sean Speese for imaging assistance and to Emma Rushton, Jeff Rohrbough, and Todd Graham for advice and critical comments. We thank the following for generously providing stocks or antibodies used in this study: Hugo Bellen, Vivian Budnik, Barry Ganetzky, Tom Jongens, Richard Ordway, Leo Pallanck, and Konrad Zinsmaier. As always, we are indebted to the Bloomington Drosophila Stock Center and the lowa Developmental Studies Hybridoma Bank.

Correspondence should be addressed to Prof. Kendal S. Broadie, Department of Biological Sciences, Vanderbilt University, VU Station B, Nashville, TN 37235-1634. E-mail: kendal.broadie@vanderbilt.edu.

D0I:10.1523/JNEUROSCI.3770-05.2006

Copyright $\odot 2006$ Society for Neuroscience $\quad$ 0270-6474/06/262369-11\$15.00/0
2004). We report here a new TS paralytic mutant, rolling blackout (rbo), which similarly reveals a novel mechanism essential for SV exocytosis.

Dissection of the molecular mechanisms of the SV cycle particularly benefits from the study of TS mutants, which provide tools to temporally dissect the interlocked pathways of SV exocytosis and endocytosis. The exocytosis pathway can be further subdivided into SV trafficking, tethering, docking, priming, and fusion at the presynaptic active zone (AZ). During the terminal stages of SV exocytosis, the priming step involves activation of NSF attachment protein (SNAP) receptor (SNARE) proteins via UNC-13-mediated opening of syntaxin and the assembly of the SNARE complex, which pulls the SV into close proximity to AZ plasma membrane to make the SV competent for $\mathrm{Ca}^{2+}$-triggered fusion (Jahn and Sudhof, 1999; Lin and Scheller, 2000; Sudhof, 2004). The fusion step itself requires regulated fusion pore opening and expansion. The SNARE complex is sufficient for in vitro liposome fusion (Weber et al., 1998), but physiological SV fusion involves other proteins/lipids acting as facilitory cofactors (Jahn and Sudhof, 1999; Lin and Scheller, 2000; Sudhof, 2004; Tucker et al., 2004). Indeed, a separate fusion machinery may act downstream of SNARE complex assembly. The actions of $\mathrm{V}_{0}$-ATPase, protein phosphatase 1 , and Vtc3p, among others, have been mapped subsequent of trans-SNARE (T-SNARE) pairing and may mediate SV fusion downstream of SNAREs (Peters et al., 1999, 2001; Muller et al., 2002; Bayer et al., 2003; Hiesinger et al., 2005). In addition to such putative fusogenic proteins, regulatory lipids such as diacylglycerol (DAG) and phosphatidylinositides [e.g., phosphatidylinositol 4,5-bisphosphate $\left(\mathrm{PIP}_{2}\right)$ ] play critical roles in exocytosis by regulating the trafficking/activation of fusogenic proteins and by directly altering membrane physical 
properties critical for SV fusion (Goni and Alonso, 1999; Peters et al., 1999; Cremona and De Camilli, 2001; Martin, 2001; Brose and Rosenmund, 2002; Di Paolo et al., 2004; Fratti et al., 2004; Jun et al., 2004; Wenk and De Camilli, 2004; Rohrbough and Broadie, 2005).

We reported previously (Huang et al., 2004) that rbo encodes an integral plasma membrane lipolytic enzyme that has an essential role in phospholipase $\mathrm{C}$ (PLC)-dependent $\mathrm{PIP}_{2} / \mathrm{DAG}$ signaling during Drosophila phototransduction (Hardie, 2003). Here, we show that RBO protein is localized to presynaptic boutons and that conditional rbo mutants are TS paralytic within minutes. At restrictive temperature, rbo TS mutants display a complete, reversible block of synaptic transmission, accumulate docked SVs at the presynaptic active zone, and display a strong synergistic genetic interaction with syntaxin mutants. These data indicate that RBO has an acute, essential role in SV exocytosis and that $\mathrm{RBO}$ likely acts in the syntaxin-dependent mechanism of SV priming/fusion or in a parallel pathway. A preliminary description of some of these results has been published (Vijayakrishnan and Broadie, 2006).

\section{Materials and Methods \\ Genetics}

Drosophila stocks were cultured on standard medium and entrained to a $12 \mathrm{~h}$ light/dark cycle at $25^{\circ} \mathrm{C}$. The wild-type (wt) strain Oregon- $\mathrm{R}$ and $w^{1118}$ were used as controls. $r b o^{t s 1}$ contains a G487D missense mutation, $r b o^{2}$ is a complete deletion null allele, $r b o^{3}$ contains an early stop codon (Q396amber), $\mathrm{df}(2 \mathrm{R}) \mathrm{H} 3 \mathrm{D} 3$ is a deficiency with break points: 044D0104;044F04-05, $r b o^{2} / r b o^{2}$; rbo-egfp/rbo-egfp is the transgenic rescue stock (Huang et al., 2004). The following TS paralytic mutant stocks were used: cacophony $\left(\mathrm{cac}^{t s 2}\right)$ (Dellinger et al., 2000), comatose $\left(\operatorname{comt}^{t s 17}, \operatorname{com}^{t 553}\right.$; kindly provided by Richard Ordway, Pennsylvania State University, University Park, PA), syntaxin1A (syx $x^{3-69}$ ) (Littleton et al., 1998), and shibire (shibire ${ }^{t s l}$; kindly provided by Barry Ganetzky, University of Wisconsin, Madison, WI).

\section{Behavioral assays}

For each genotype, 20 males and 20 females were tested. In each session, animals were transferred into a prewarmed transparent plastic tube and placed at the indicated temperature in a hybridization oven $(\mathrm{HO} 6000 \mathrm{~V}$; GeneMate; ISC BioExpress, Kaysville, UT). Animals were observed continuously and the paralysis time point for each individual recorded. Paralysis was defined when an animal was inverted and immobile at the bottom of the tube, lacking any detectable leg movement. Paralyzed animals were transferred to room temperature (RT) to assay recovery time. The recovery time point was recorded when each animal achieved a standing position and could walk when provoked. The veratridine (Sigma, St. Louis, MO) resistance assay was done as described previously (Chandrashekaran, 1993) with slight modification: equal numbers of male and female animals were used, with assays done at 18,22 , and $28^{\circ} \mathrm{C}$. Each genotype was introduced separately into vials with a $1.5 \mathrm{~cm}$ disk of filter paper containing $100 \mu \mathrm{g}$ of veratridine in $2 \%$ sugar. Animals were counted at $2,4,8$, and $24 \mathrm{~h}$.

\section{Immunocytochemistry}

$\mathrm{RBO}-$ enhanced green fluorescent protein (eGFP) imaging was performed on transgenic rescue animals $\left(r b o^{2} / r b o^{2}\right.$; rbo-egfp/rbo-egfp), with the expression of RBO-eGFP protein under the control of the endogenous rbo promoter (Huang et al., 2004). For immunocytochemistry, dissected preparations were fixed in $4 \%$ paraformaldahyde in PBS at RT for $25 \mathrm{~min}$ (larvae) and $45 \mathrm{~min}$ (adults). Preparations were incubated in the following primary antibodies for at least $2 \mathrm{~h}$ at RT: anti-discs large (DLG; 1:1000; rabbit; from Vivian Budnik, University of Massachusetts Medical School, Worcester, MA), anti-cysteine string protein (CSP; 1:500; mouse; from Konrad Zinsmaier, University of Arizona, Tucson, AZ), anti-synaptotagmin (1:5000; rabbit; from Hugo Bellen, Baylor College of Medicine, Houston, TX), Texas Red-conjugated anti-HRP (1:300; goat; Jackson ImmunoResearch, West Grove, PA), FITC-conjugated
anti-HRP (1:500; goat; Jackson ImmunoResearch), and anti-dUNC13 [1:500; rabbit (A2)] (Aravamudan and Broadie, 2003). Preparations were incubated for $1 \mathrm{~h}$ at RT with secondary antibodies (1:1000; Invitrogen, San Diego, CA). Images were captured on a Bio-Rad (Hercules, CA) Radiance 2000 or Zeiss (Oberkochen, Germany) LSM 510 Meta confocal microscope.

\section{Electrophysiology}

Excitatory junctional potential recording in giant fiber system. An adult animal anesthetized by $\mathrm{CO}_{2}$ was mounted ventral side down on a glass coverslip with dental soft wax under a dissection microscope. A HCC100A temperature controller (Dagan, Minneapolis, MN) was used for temperature control. The tip of the temperature probe was embedded in the wax; it took $\sim 2 \mathrm{~min}$ to increase temperature from 25 to $37^{\circ} \mathrm{C}$. The output from the temperature controller was transited for simultaneous recording of temperature and electrical signals. A glass reference electrode was inserted into the abdomen, and a glass stimulating electrode was inserted into each eye (Pavlidis and Tanouye, 1995). A glass recording electrode $(3 \mathrm{M} \Omega$ ) was driven through the dorsal thorax cuticle. Intracellular penetration into the muscle was monitored by a sudden potential drop of $40-60 \mathrm{mV}$. The muscle identity [dorsal longitudinal muscle (DLM) vs tergotrochanteral muscle (TTM)] was determined by electrode placement and verified by recorded latency time. Signals were amplified by IX1 intracellular preamplifier (Dagan) and digitized at 100 kHz by Digidata 1200 or 1322A (Molecular Devices, Union City, CA). Data were collected and analyzed with pClamp software (version 8.0; Molecular Devices). All glass electrodes were filled with $3 \mathrm{M} \mathrm{KCl}$.

Excitatory junctional current recording in DLM muscle cells. An adult animal was laterally mounted over an opening of a Parafilm tube and secured with soft dental wax so that air was accessible to the trachea. The overlying cuticle and muscles were dissected away to expose one set of DLM cells in $\mathrm{Ca}^{2+}$-free saline consisting of the following (in $\mathrm{mM}$ ): 128 $\mathrm{NaCl}, 2 \mathrm{KCl}, 4 \mathrm{MgCl}_{2}, 5 \mathrm{HEPES}$, and 36 sucrose. The dissection saline was then replaced with $1.8 \mathrm{mM} \mathrm{CaCl}_{2}$ recording saline, perfused at $0.3-0.4$ $\mathrm{ml} / \mathrm{min}$. The posterior dorsal mesothoracic nerve carrying the DLM motor neuron (DLMn) axons was cut and sucked into a glass stimulation pipette (Koenig et al., 1983). Two glass microelectrodes $(\sim 10 \mathrm{M} \Omega$ ) filled with $3 \mathrm{M} \mathrm{KCl}$ were inserted in the DLMe (e cell of the DLM) or DLMd (d cell of the DLM) cell. The DLM resting potentials ranged from -70 to $-90 \mathrm{mV}$. Two-electrode voltage clamp was performed using an Axoclamp-2B amplifier (Molecular Devices), with the holding potential at $-80 \mathrm{mV}$ (Kawasaki et al., 1998) and the voltage-clamp gain over 50. The HCC-100A temperature controller was again used for temperature control, with coincident recording of temperature and electrical signals. Data were analyzed with pClamp software (version 8.0; Molecular Devices).

Recording at the larval neuromuscular junction. Standard larval neuromuscular junction (NMJ) recording configurations were used (Broadie, 2000). Briefly, recordings were made from muscle 6 in abdominal segments A3-4 of wandering third instar larva using two-electrode voltageclamp $(-60 \mathrm{mV})$ techniques (Axoclamp 2B amplifier). Intracellular recording electrodes were filled with $3 \mathrm{M} \mathrm{KCl}$ and typically had a resistance of $\sim 10 \mathrm{M} \Omega$. Excitatory junctional currents (EJCs) were evoked by brief stimuli $(0.4-1.5 \mathrm{~ms})$ applied to the cut motor nerve using a suction electrode. The recording saline contained the following (in $\mathrm{mm}$ ): 128 $\mathrm{NaCl}, 2 \mathrm{KCl}, 4 \mathrm{MgCl}_{2}, 5$ trehalose, 70 sucrose, 5 HEPES, and $1.8 \mathrm{CaCl}_{2}$, $\mathrm{pH}$ 7.1. A probe placed close to the preparation monitored the recording chamber temperature. Data acquisition and analysis were performed using pClamp software (version 8.0; Molecular Devices).

\section{Dye imaging}

FM1-43 dye imaging was performed as described previously (Fergestad and Broadie, 2001) with slight modifications. Wandering third instar larvae or adults were dissected in $\mathrm{Ca}^{2+}$-free recording with mutants and controls always prepared in the same chamber to ensure identical processing and imaging conditions (Fergestad and Broadie, 2001). The preparations were exposed to $10 \mu \mathrm{M}$ FM1-43 (Invitrogen) in $90 \mathrm{mM} \mathrm{K}^{+}$saline containing $1.8 \mathrm{~mm} \mathrm{Ca}^{2+}$ (Fergestad and Broadie, 2001) for 3-5 min to load synaptic terminals, then washed in $\mathrm{Ca}^{2+}$-free recording saline (2 
$\mathrm{mm} \mathrm{K}^{+}$) for $\sim 10 \mathrm{~min}$, while the saline was exchanged at least three times. Confocal fluorescence images were acquired with a Zeiss LSM 510 confocal microscope. In each animal, NMJs were imaged, and then samples were transferred to prewarmed $\left(38^{\circ} \mathrm{C}\right) \mathrm{Ca}^{2+}$-free recording saline and moved to a $38^{\circ} \mathrm{C}$ incubator for $15 \mathrm{~min}$. Samples were then treated with prewarmed $\left(38^{\circ} \mathrm{C}\right)$ high- $\mathrm{K}^{+}$saline for 5 min to destain terminals, and confocal imaging was then repeated using identical parameters.

\section{Electron microscopy}

Animals at room temperature $\left(22^{\circ} \mathrm{C}\right)$ or incubated for $10 \mathrm{~min}$ at $37^{\circ} \mathrm{C}$ were fixed in $2.5 \%$ glutaraldeyde overnight. Samples were then washed in PBS for $10 \mathrm{~min}$, transferred to $1 \%$ osmium tetroxide in $\mathrm{H}_{2} \mathrm{O}$ for $1 \mathrm{~h}$, rinsed with double-distilled $\mathrm{H}_{2} \mathrm{O}$, and stained en bloc in $2 \%$ aqueous uranyl acetate for $1 \mathrm{~h}$. Samples were then dehydrated through a series of graded alcohols and embedded in Araldite. After placing in a vacuum oven for $30 \mathrm{~min}$, animals were placed in fresh Araldite and left to polymerize overnight at $60^{\circ} \mathrm{C}$. Ribbons of thin $(\sim 40-50 \mathrm{~nm})$ sections were obtained with a Leica (Nussloch, Germany) Ultracut UCT 54 ultramicrotome and examined on a Phillips CM12 TEM, equipped with a 2 megapixel CCD camera. Digital electron microscopy (EM) images were taken of synaptic boutons from the DLM NMJ. All sections for quantification contained at least one clear presynaptic T-bar, defining an AZ, identified in at least two consecutive sections. Docked vesicles were defined as those within $20 \mathrm{~nm}$ from the electron dense presynaptic membrane at the T-bar, as described previously (Aravamudan et al., 1999). Morphometric analysis was performed using the public domain NIH ImageJ software package.

\section{SNARE complex assay}

Animals at room temperature $\left(22^{\circ} \mathrm{C}\right)$, or incubated for 10 min at 33 or $37^{\circ} \mathrm{C}$, were frozen in liquid nitrogen, and heads were immediately collected with a sieve. One hundred fifty milligrams of heads were homogenized in $3 \mathrm{ml}$ of ice-prechilled hypotonic buffer $\left[10 \mathrm{mM} \mathrm{MgCl}_{2}, 25 \mathrm{mM}\right.$ Tris, pH 7.4, 2.5 mm EGTA, and complete mini-protease inhibitor mixture (Roche Products, Welwyn Garden City, UK)] with a dounce homogenizer. Plasma membrane fractions were collected from the lysed cell suspension by centrifugation at $1000 \times g\left(5 \mathrm{~min}, 4^{\circ} \mathrm{C}\right)$ and subsequent centrifugation of the supernatant at 50,000 $\times g\left(30 \mathrm{~min}, 4^{\circ} \mathrm{C}\right)$. Protein extraction was performed by resuspending the final membrane pellet in SDS sample buffer (50 mm Tris-HCl, pH 6.8, 10\% glycerol, 2\% SDS, 5\% 2 -mercaptoethanol) for $15 \mathrm{~min}$ at $22^{\circ} \mathrm{C}$. Total membrane protein concentration was determined by absorbance measurements at $280 \mathrm{~nm}$. Bromophenol blue was added $(0.03 \%)$, and samples were subjected to SDSPAGE and Western blot with primary antibody against syntaxin1A (8C3; Developmental Studies Hybridoma Bank, University of Iowa, Iowa City, IA), SNAP25 (Leo Pallanck, University of Washington, Seattle, WA), and HRP-conjugated secondary antibodies (Promega, Madison, WI). Signals were visualized by ECL and quantified by LabWorks 4.5 in combination with UVP (Upland, CA) BioImaging systems.

\section{Statistics}

Statistical analyses of total SV number, bouton size, and the docked SV number at active zones were done with InStat (GraphPad Software, San Diego, CA); significant differences were determined by the nonparametric Mann-Whitney test. Statistical analyses of all other experiments were done with Microsoft (Redmond, WA) Excel X software; significant changes were determined by an unpaired $t$ test. In all cases, $p$ values $<0.05$ were considered significant. If not specified, data are represented by mean \pm SEM.

\section{Results}

\section{$\mathrm{RBO}$ is acutely required for movement}

At permissive temperatures $\left(\leq 25^{\circ} \mathrm{C}\right)$, rbo TS mutant adult flies appear to act normally and cannot be distinguished from wt based on locomotion or gross behavior. At restrictive temperature $\left(\geq 37^{\circ} \mathrm{C}\right)$, all $r$ bo TS mutant animals are completely paralyzed within minutes, although control animals appear unaffected. At intermediate temperatures, rbo TS mutants show intermediate movement impairment. At $29^{\circ} \mathrm{C}$, mutants remain mobile for
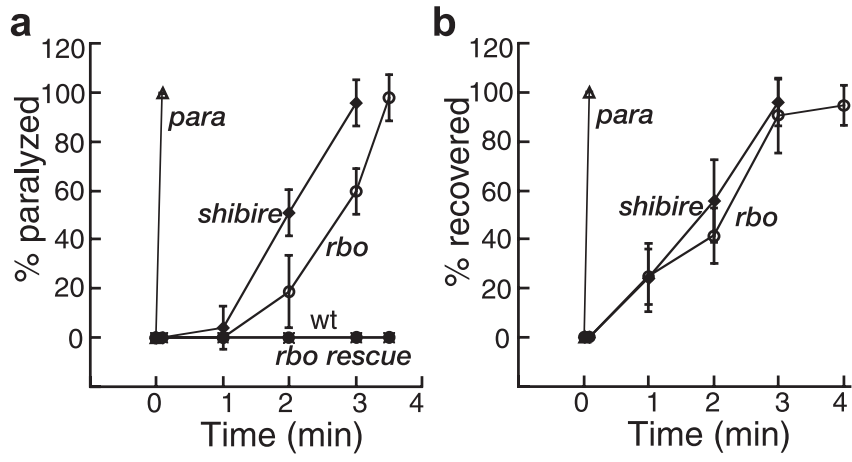

Figure 1. TS paralysis and recovery of rbo mutants. $\boldsymbol{a}, \boldsymbol{b}$, The kinetics of TS paralysis at $37^{\circ} \mathrm{C}$ (a) and recovery from paralysis at room temperature $\left(22^{\circ} \mathrm{C}\right)(\boldsymbol{b})$. The genotypes are Oregon- $R$

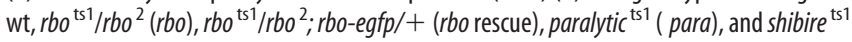
(shibire) homozygous mutants. Error bars represent SD.

many hours but become progressively sluggish and die within $1 \mathrm{~d}$, and at $33^{\circ} \mathrm{C}$, mutants display reduced movement followed by complete paralysis in $\sim 30 \mathrm{~min}$. Thus, rbo TS mutants display a progressively temperature-dependent impairment in some mechanism required for movement.

The kinetics of reversible paralysis was quantified in a range of homozygous and trans-heterozygous $r b o$ mutants $\left(r b o^{t s l} / r b o^{t s l}\right.$, $r b o^{t s 1} / r b o^{2}, r b o^{t s l} / r b o^{3}, r b o^{t s 1} / D f(2 R) H 3 D 3$; see Materials and Methods). The time course of paralysis and recovery are shown in Figure 1. All rbo mutant allelic combinations display 100\% paralysis within 3-4 min when shifted from room temperature $\left(22^{\circ} \mathrm{C}\right)$ to $37^{\circ} \mathrm{C}$ and recover with a similar time course after a return to room temperature (Fig. 1). Control wild-type and rbo/+ flies show no movement impairment under identical conditions. No difference in the kinetics of paralysis or recovery was observed between $r b o^{t s 1}$ homozygotes and $r b o^{t s 1} / r b o^{2}, r b o^{t s 1} / r b o^{3}, r b o^{t s 1} /$ $D f(2 R) H 3 D 3$ mutants (data not shown). A single copy of a wildtype rbo:egfp transgene fully rescues behavioral paralysis in all of these genotypes (Fig. 1a). Therefore, the temperature-sensitive paralysis can be fully ascribed to the $r b o^{t s 1}$ mutation.

To gain insight into possible mechanisms, we compared $r b o^{t s 1}$ mutants with paralytic ${ }^{t_{s} 1}$ [terminates action potentials (APs) (Wu and Ganetzky, 1980)] and shibire ${ }^{t s l}$ [blocks SV endocytosis (Koenig et al., 1983)]. The paralysis and recovery kinetics of $r b o^{t s 1}$ differs markedly from paralytic ${ }^{t s 1}$, in which paralysis/recovery are exceedingly rapid $(\sim 5 \mathrm{~s})$ (Fig. 1). This result suggests that $r b o$ is unlikely to encode a protein directly mediating neuronal excitability, such as an ion channel or channel regulator. Consistent with this conclusion, $r b o^{t s l}$ mutants do not show any visible change in death rate after exposure to veratridine for $2,4,8$, and $12 \mathrm{~h}$ at 18,22 , and $28^{\circ} \mathrm{C}$ (data not shown). Veratridine is a sodium channel-specific neurotoxin that prolongs the activation of voltage-gated $\mathrm{Na}^{+}$channels (Ritchie, 1979; Suzuki and $\mathrm{Wu}$, 1984; Jackson et al., 1986). $\mathrm{Na}^{+}$channel mutants and $\mathrm{Na}^{+}$channel regulator mutants display increased resistance to veratridine at both permissive and restrictive temperatures, including para $^{\text {ts }}$, $n a p^{t s}$, and tipE (Suzuki and $\mathrm{Wu}, 1984$; Jackson et al., 1986). Furthermore, $r b o^{t s l}$ mutants do not show genetic interaction with paralytic ${ }^{\text {ts } 1}$, shaker $\left(I_{\mathrm{A}}\right.$ voltage-gated $\mathrm{K}^{+}$channel), or ether-a-gogo (a subunit common to different $\mathrm{K}^{+}$channels) mutants in terms of the kinetics of TS paralysis and recovery (data not shown).

The paralysis kinetics of $r b o^{t s 1}$ and shibire $e^{t s 1}$ mutants is quite comparable; $r b o^{t s l}$ mutants paralyze slightly more slowly than shibire $^{t s l}$ (Fig. 1a) but recover with an indistinguishable time course (Fig. 1b). The relatively slow paralysis/recovery in shibire $e^{t s 1}$ 
is caused by slow depletion/regeneration of the synaptic vesicle pool (Koenig et al., 1983). Similarly, there is an activitydependent requirement for $\mathrm{RBO}$ in phototransduction (Huang et al., 2004), and loss of RBO function likely results in the loss of some resource limiting neurotransmission. Given that RBO is an integral plasma membrane lipase (Huang et al., 2004), one likely possibility is that $\mathrm{RBO}$ produces a limiting lipid required for neurotransmission or, alternatively, eliminates a lipid that negatively regulates neurotransmission.

\section{$\mathrm{RBO}$ is subcellularly restricted to neuronal synapses}

A $r b o-e g f p$ fusion transgene was made from genomic DNA including $3.5 \mathrm{~kb}$ upstream and $1.5 \mathrm{~kb}$ downstream of the rbo coding region. A single copy of this rboegfp transgene rescues all rbo mutant phenotypes (Huang et al., 2004). We therefore examined rbo-egfp expression in the rbo null mutant background. Previously, we showed RBO-eGFP protein to be highly enriched in the central synaptic neuropil of embryos, larvae, and adults, in the brain and the thoracic and abdominal ganglia (Huang et al., 2004). To examine RBO expression within individual, identified neurons, we assayed motor neurons and NMJ synapses in both larvae and adults (Fig. 2).

$\mathrm{RBO}$ protein is undetectable in neuronal soma, present at low levels in axons, and highly enriched specifically within synaptic boutons (Fig. 2). RBO protein is expressed at all examined NMJ synapses innervating the body musculature in both larva (Fig. $2 a$ ) and adult stages (Fig. 2b). Double-labeling experiments with either presynaptic (synaptotagmin, CSP, HRP) or postsynaptic (DLG) markers confirms that RBO is specifically subcellularly enriched within synaptic boutons (Fig. 2). The expression pattern is consistent with a predominantly presynaptic localization for RBO, although a low level of muscle postsynaptic localization may also occur. RBO is associated with the plasma membrane throughout the synaptic bouton, without any detectable restriction in smaller membrane domains (Fig. $2 a$, insets). This expression pattern, together with the rbo TS paralytic phenotype, suggests that RBO functions in synaptic transmission to mediate coordinated movement.

\section{$\mathrm{RBO}$ is required for synaptic transmission}

To investigate whether the adult conditional rbo paralysis is associated with a failure in synaptic transmission, EJP recordings were made in the adult GF escape circuit (Fig. 3), well characterized in terms of both anatomy and physiology (King and Wyman, 1980; Tanouye and Wyman, 1980; Ikeda and Koenig, 1988; Trimarchi and
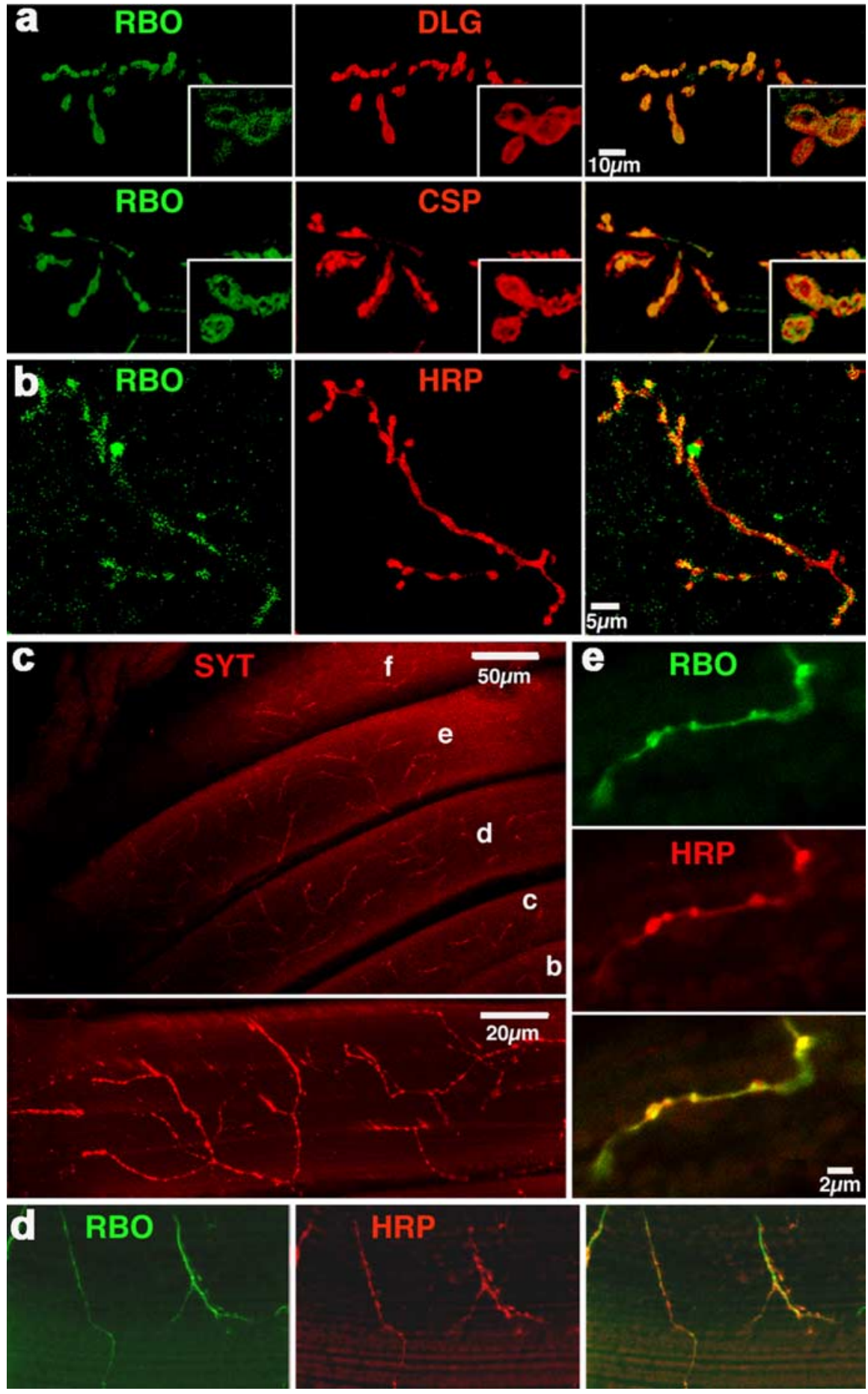

Figure 2. RBO protein is subcellularly restricted to synapses. Confocal imaging of RBO-eGFP in rbo transgenic rescue background $\left(r b o^{2} / r b o^{2} ; r b o-e g f p / r b o-e g f p\right) . a$, RBO at wandering third instar larva NMJ synapses. Colocalization of RBO with synaptic markers is shown (DLG, predominantly postsynaptic and (SP, a presynaptic vesicle-associated protein). $\boldsymbol{b}$, RBO in adult abdominal NMJs. Anti-HRP recognizes the neuronal membrane. $c$, Innervation pattern of DLM NMJs stained with anti-synaptotagmin. NMJs are deeply embedded and evenly distributed in DLM muscle cells. The bottom is the projection of a single DLM muscle cell. $\boldsymbol{d}, \boldsymbol{e}$, Lower amplification $(\boldsymbol{d})$ and higher amplification (e), showing that RBO colocalizes with HRP in DLM NMJs.

Murphey, 1997). GF circuit activation involves stimulation of the giant neuron in the brain, AP propagation through the GF into the thoracic ganglion, electrical synapse activation of the peripherally synapsing interneuron (PSI), cholinergic synapse activation of the DLMn, AP propagation along DLMn axon in the peripheral nerve, and finally NMJ glutamatergic transmission at the muscle (Fig. 2c). Records were made by electrically stimulating the paired giant neu- 

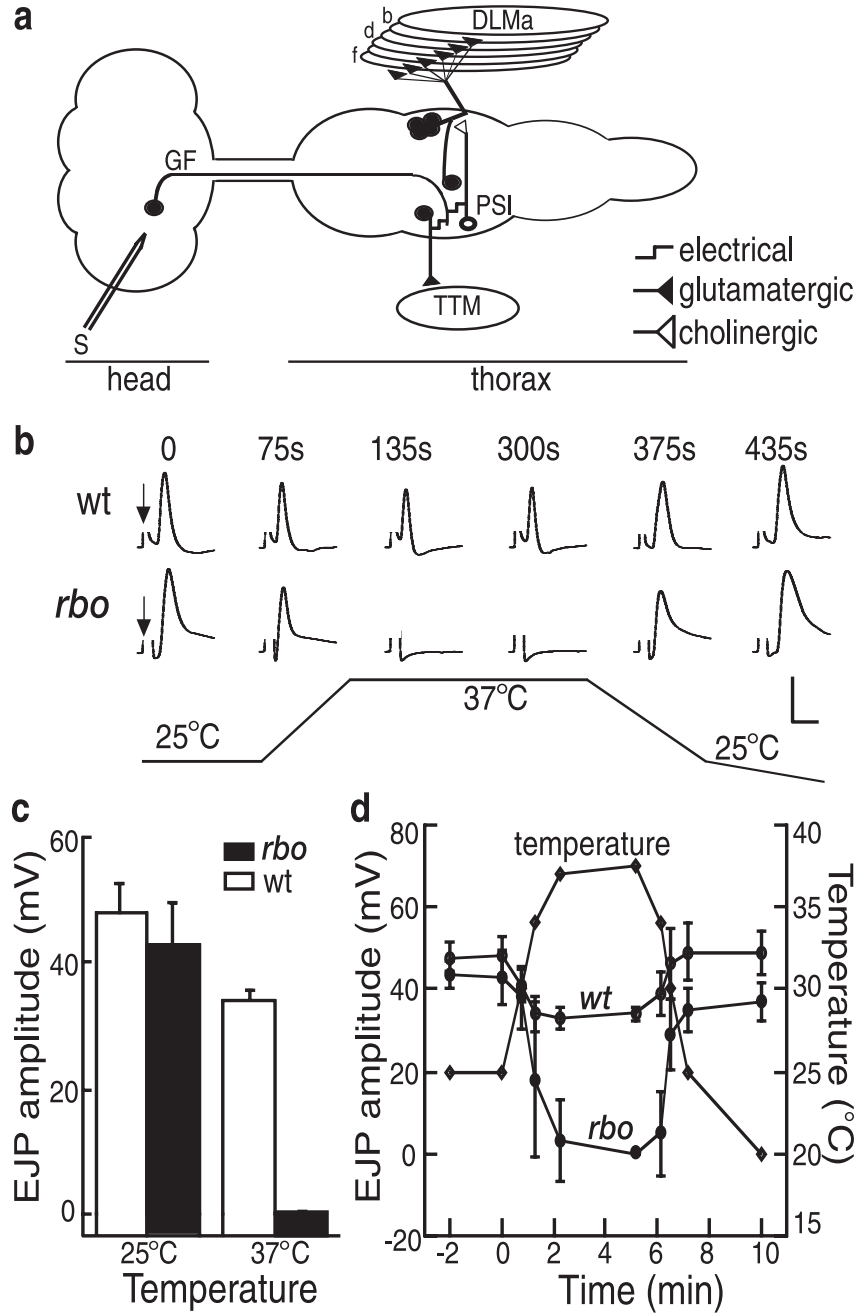

Figure 3. Conditional block of neurotransmission in the giant fiber circuit. $\boldsymbol{a}$, Schematic diagram of the GF circuit. Note in particular that output onto the TTM requires only electrical synapses before the glutamatergic NMJ, whereas output onto the DLM has a single prerequisite central chemical (cholinergic) synapse between the PSI interneuron and the motor neuron. Stimulation (S) was applied to the brain to activate the GF and in turn activate the motor neurons. $\boldsymbol{b}$, Representative traces of the temperature-dependent, reversible loss of DLM EJP responses in wt and $r b o\left(r b 0^{t s 1} / r b o^{2}\right)$ mutants (arrow indicates shock artifact; removed for clarity). The bottom trace shows the concurrently recorded temperature shift ( 25 to $37^{\circ} \mathrm{C}$ ). C, Quantification of EJP amplitude at $25^{\circ} \mathrm{C}$ and after 5 min at $37^{\circ} \mathrm{C}$. The bars show the mean \pm SD. $\boldsymbol{d}$, Time course of EJP amplitude changes. The recording temperature (right axis) was recorded simultaneously.

rons in the brain with extracellular glass electrodes while intracellularly recording output in thoracic DLM muscles (Fig. $3 a$ ).

At permissive temperature $\left(25^{\circ} \mathrm{C}\right)$, evoked EJP amplitudes in $r b o^{t s 1}$ mutants are indistinguishable from wild type $\left(r b o^{t s 1} / r b o^{2}\right.$, $43 \pm 6.6 \mathrm{mV}, n=8$; wt, $48 \pm 4.6 \mathrm{mV}, n=7$ ) (Fig. $3 b, c$ ). In contrast, after a shift to $37^{\circ} \mathrm{C}$, evoked EJPs in $r b o^{t s 1}$ mutants are undetectable and remain completely suppressed at $37^{\circ} \mathrm{C}$, but then recover after return to $25^{\circ} \mathrm{C}$ (Fig. $3 b-d$ ). In wild type, EJP amplitudes are reduced by $\sim 25 \%$ at $37^{\circ} \mathrm{C}(36 \pm 1.8 \mathrm{mV})$ but persist throughout the entire time course of the temperature shift recording (Fig. $3 b-d$ ). These results show that adult conditional paralysis in $\mathrm{rbo}^{t s 1}$ mutants temporally correlates with neural transmission blockade in the adult GF circuit. Interestingly, there is not a similar acute requirement for $\mathrm{RBO}$ at the larval NMJ. EJC amplitudes at room temperature $\left(20-22^{\circ} \mathrm{C}\right)$ were indistinguishable between $r b o^{t s 1}$ and control animals $\left(r b o^{t s 1} / r b o^{2}, 185 \pm 19 \mathrm{nA}\right.$, $n=5$; wild type, $190 \pm 10 \mathrm{nA}, n=5$ ). Incubation of $r b o^{t s 1}$ wandering third instars at $37^{\circ} \mathrm{C}$ did not cause significant change in EJC amplitudes. At a stimulation frequency of $0.5 \mathrm{~Hz}$, mean EJC amplitude was $243 \pm 18 \mathrm{nA}$ for $r b o^{t s 1} / r b o^{2}(n=6)$ and $224 \pm$ $24 \mathrm{nA}(n=6)$ for control animals, respectively. In all recordings, EJCs could be evoked as long as a stable recording configuration was maintained $\left(>15 \mathrm{~min}\right.$ at $\left.37^{\circ} \mathrm{C}\right)$, essentially excluding the possibility of a delayed onset of transmission impairment. Similarly, assays of SV cycling with FM1-43 dye loading/unloading at the larval NMJ failed to reveal deficits in $r b o^{t s 1} / r b o^{2}$ mutants (data not shown). Therefore, the acute requirement for RBO in maintaining neural transmission appears restricted to the adult.

The EJP loss in adult $r b o^{t s 1}$ mutants could be caused by a defect at any level of GF circuit function, including failure of AP initiation/propagation or a blockade of synaptic transmission at either central or peripheral synapses. To distinguish between these possibilities, we took advantage of the dual DLM and TTM outputs of the GF circuit (Fig. 3a). The DLM circuit contains a single, essential cholinergic chemical synapse between PSI and DLMn, upstream of the glutamatergic DLM NMJ, and thus behaves like a bisynaptic pathway. In contrast, the TTM glutamatergic NMJ is the sole required chemical synapse in the TTM circuit (King and Wyman, 1980): electrical synapses alone are sufficient for transmission to the TTM NMJ, which therefore behaves like a monosynaptic pathway. Any block of AP function would result in an abrupt failure of neural transmission in both outputs of the GF circuit. In contrast, any direct loss of synaptic function would be predicted to differentially block function in the two outputs. If $\mathrm{RBO}$ is required only at glutamatergic NMJs, we would expect both DLM and TTM EJPs to be lost in a graded, incremental manner over several minutes, as NMJ synaptic transmission is progressively degraded. If $\mathrm{RBO}$ is also required for central transmission, we would predict that a blockade of the weaker cholinergic PSI synapse will lead to a failure of AP initiation in the DLMn, causing a sudden, complete loss of NMJ transmission. Similarly, if a central transmission block occurs, we would predict an abrupt recovery of the DLM EJP once the central transmission recovers versus an incremental improvement of the TTM EJP.

The results of the DLM/TTM comparison strongly indicate that rbo mutants are specifically defective in synaptic transmission in both central and peripheral synapses (Fig. 4). In DLM recordings in $r b o^{t s l}$ mutants after shift to restrictive temperature ( 25 to $37^{\circ} \mathrm{C}$ ), the EJP initially declines, consistent with a progressive weakening of NMJ transmission, but then displays a sudden complete loss (Fig. $4 a$, middle). In contrast, TTM recording of $r b o^{t s 1}$ mutants always show a gradual loss of EJP amplitude over several minutes after shift to the restrictive temperature (Fig. $4 b$, middle) and a similar gradual recovery after return to permissive temperature (Fig. $4 b$, right). The time to complete EJP loss at restrictive temperature was $4.3 \pm 0.5 \min$ (mean $\pm \mathrm{SD} ; n=6$ ), which agrees well with the time to complete TS paralysis (4.5 min). DLM and TTM EJPs in wild-type and transgenic rescue flies $\left(r b o^{t s l} / r b o^{2} ; r b o-e g f p /+\right)$ persist through the entire recording course (Fig. $4 a, b$, left).

These results predict that the DLM should show graded block/ recovery if the presumed upstream block in the cholinergic PSI synapse could be bypassed. To test this prediction, we used an extracellular electrode placed in the thoracic ganglion to directly excite the DLM motor neuron axon. As predicted, under this stimulation paradigm, the DLM in $r b o^{t s 1} / r b o^{2}$ shows graded loss/recovery of EJP amplitude with a time course comparable with the TTM (Fig. 4a, right) $(n=5)$. Thus, the abrupt loss/recovery of the EJP in the DLM is caused by a central (PSI-DLMn) synaptic defect, superimposed on 
a simultaneous NMJ transmission blockade. DLM EJPs evoked by brain stimulation require one or more central chemical synaptic relays (Tanouye and Wyman, 1980; Trimarchi and Murphey, 1997; Kawasaki and Ordway, 1999). Impairment of central synaptic transmission results in longer latencies of DLM EJPs (Kawasaki and Ordway, 1999). The presumed block of PSI-DLMn transmission in $r b o^{t s 1}$ predicts a slowing of AP generation in DLMn and therefore a longer latency of DLM EJP. To test this, we quantified the latencies of DLM EJP in wild type and in $r b o^{t s 1} / r b o^{2}$. During temperature elevation, both wild-type and mutant DLM EJP latencies first transiently shorten, but then begin to increase at $\sim 33^{\circ} \mathrm{C}$. Above $33-35^{\circ} \mathrm{C}$, $r b o^{t s 1} / r b o^{2}$ latencies are significantly prolonged compared with control (Fig. $4 a$, left and middle, $d$ ).

The EJPs recorded in DLM/TTM are composed of both a synaptically generated postsynaptic potential and a voltage-dependent electrogenic potential (Koenig et al., 1983; Kawasaki and Ordway, 1999). To directly examine synaptic conductance in $r b o^{t s l}$ mutants, we performed two-electrode voltage-clamp EJC recordings from DLMe/d cells (Fig. 4d). The cut motor nerve was stimulated via a suction pipette, and muscle cells were clamped at $-80 \mathrm{mV}$. TTX was added to the perfusion solution $(0.25 \mu \mathrm{M})$ to block action potentials in nerve, allowing direct, passive depolarization of the NMJ terminal. EJCs were evoked by constant $0.1 \mathrm{~Hz}$ stimulation, and traces were captured at three time points: (1) the initial responses at $25^{\circ} \mathrm{C},(2)$ after $3 \mathrm{~min}$ at $36^{\circ} \mathrm{C}$, and (3) after return to $25^{\circ} \mathrm{C}$ (Fig. $4 \mathrm{c}$ ). At $25^{\circ} \mathrm{C}$, EJC amplitude in wild-type and $r b o^{t s l}$ mutants were indistinguishable (wt, $3.32 \pm 0.12 \mu \mathrm{A}, n=5$; $r b o^{t s 1} / r b o^{2}, 3.0 \pm 0.29 \mu \mathrm{A}, n=5$ ) (Fig. $4 c$ ). At $36^{\circ} \mathrm{C}, r b o^{t s 1} / r b o^{2}$ EJCs are completely abolished, but wild-type EJCs remain robust $(2.88 \pm 0.16 \mu \mathrm{A})$ throughout the entire course of the recording. After a return to $25^{\circ} \mathrm{C}$, mutant transmission recovers to $87 \%$ of the initial amplitude $(2.34 \pm 0.23 \mu \mathrm{A})$ (Fig. 4c). Together, these results demonstrate that $\mathrm{RBO}$ is required in a time course of minutes for both peripheral glutamatergic NMJ and central cholinergic PSI-DLMn synaptic transmission.

\section{$\mathrm{RBO}$ is required for synaptic} vesicle exocytosis

Our next objective was to determine the mechanistic requirement for RBO in synaptic transmission. We first attempted to perform FM1-43 loading and unloading to assay SV endocytosis and exocytosis, respectively. Unfortunately, we were unsuccessful in stimulating significant dye uptake at the adult DLM/TTM NMJs, presumably because these NMJs are embedded deeply within the muscle fibers (Fig. $2 c$ ) and poorly accessible to the applied dye. We therefore directly
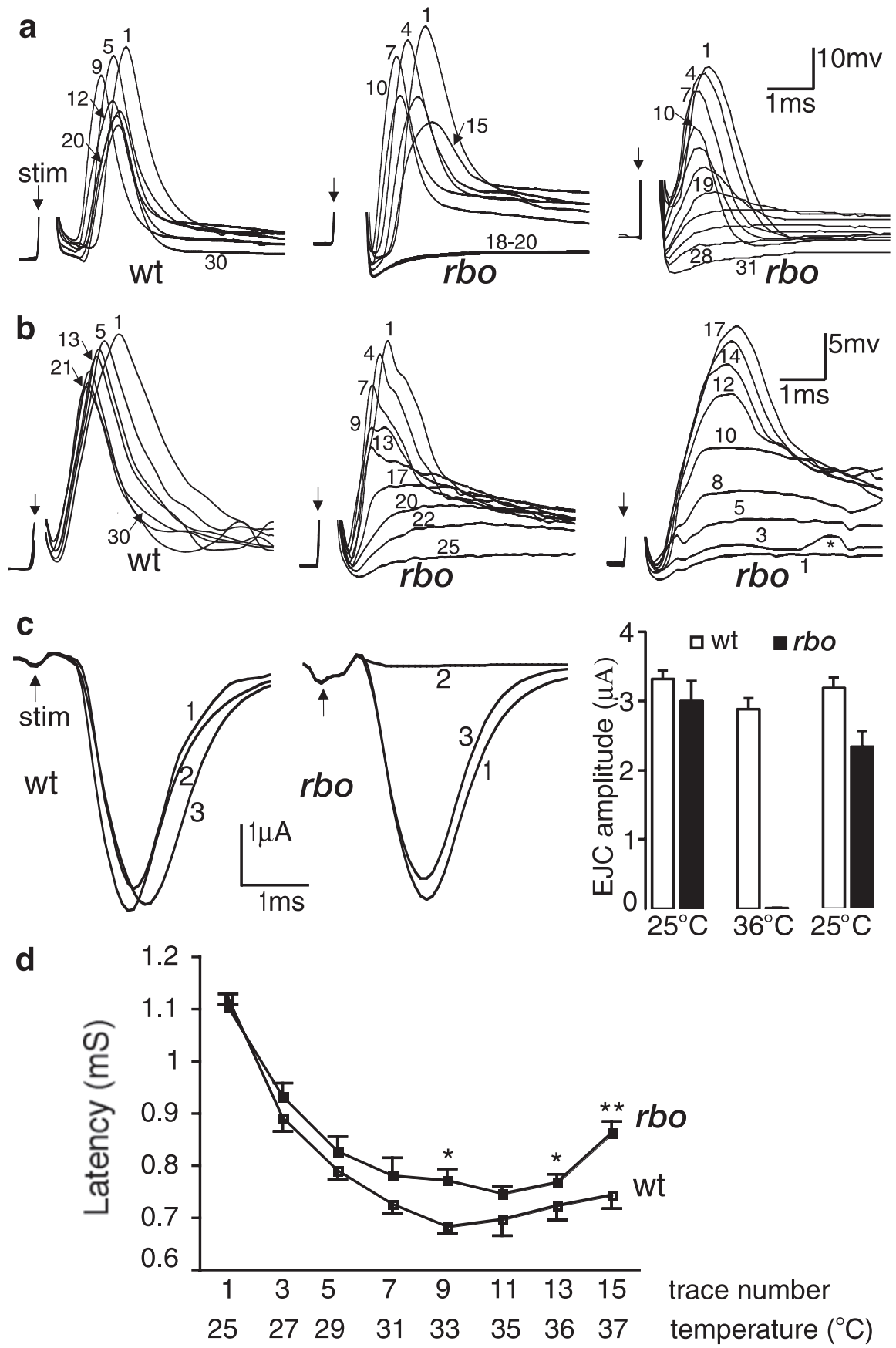

Figure 4. The rbo TS mutation specifically blocks synaptic transmission. $\boldsymbol{a}$, Representative series of EJP traces from the DLM evoked by $0.1 \mathrm{~Hz}$ brain or thoracic stimulation (arrow) during temperature shift from 25 to $37^{\circ} \mathrm{C}$. The numbers indicate order of the evoked response. Response amplitudes are reduced slightly in both genotypes during the temperature shift but persist in wt (left) and fail in an abrupt manner in $r b o\left(r b o^{t s} / / r b 0^{2}\right)$ mutants when evoked by brain stimulation (middle). However, rbo DLMEJP shows gradual loss when induced by direct-simulating DLM motor neuron (right). $\boldsymbol{b}$, Representative series of TTM ESP traces from wt and $r b$ o transgenic rescue $\left[\left(\mathrm{rbo}^{\mathrm{ts}} \mathrm{r} / \mathrm{rbo}^{2}\right.\right.$; rbo-egfp/+ (left) and $r b o$ (middle and right)]. The left and middle panels show EJP responses during temperature shift from 25 to $37^{\circ} \mathrm{C}$, whereas the right shows the EPP recovery when temperature is returned to $25^{\circ} \mathrm{C}$. Note the graded loss of EJP amplitude after shift to restrictive temperature (middle) and the graded recovery of EJP amplitude after shift back to permissive temperature (right).c, Reversible block of EJC in DLM NMJs in rbo mutants. Representative traces at $25^{\circ} \mathrm{C}(1), 36^{\circ} \mathrm{C}(2)$, and after return to $25^{\circ} \mathrm{C}(3)$ in both wt (left) and $r b o$ (middle) mutants are shown. $\boldsymbol{d}$, Quantification ofEJCamplitudes; $n=5$ for each genotype. $\boldsymbol{e}$, Quantification of latency of DLM EPPs evoked by brain stimulation in wt and rbo mutants during temperature shift from 25 to $37^{\circ} \mathrm{C}$. ${ }^{*}$ and ${ }^{* *}$ indicate significant $(p<0.05)$ and highly significant $(p<0.01)$ change, respectively; $n=5$ for each genotype. The bars show the mean \pm SEM. stim, Stimulation.

turned to electron microscopy to perform ultrastructural studies of DLM NMJs of both wild type and $r b o^{t s l}$ mutants. EM studies were performed both at permissive room temperature $\left(22^{\circ} \mathrm{C}\right)$, in which mutants show no functional defects (Figs. 3, 4), and 10 min after a 

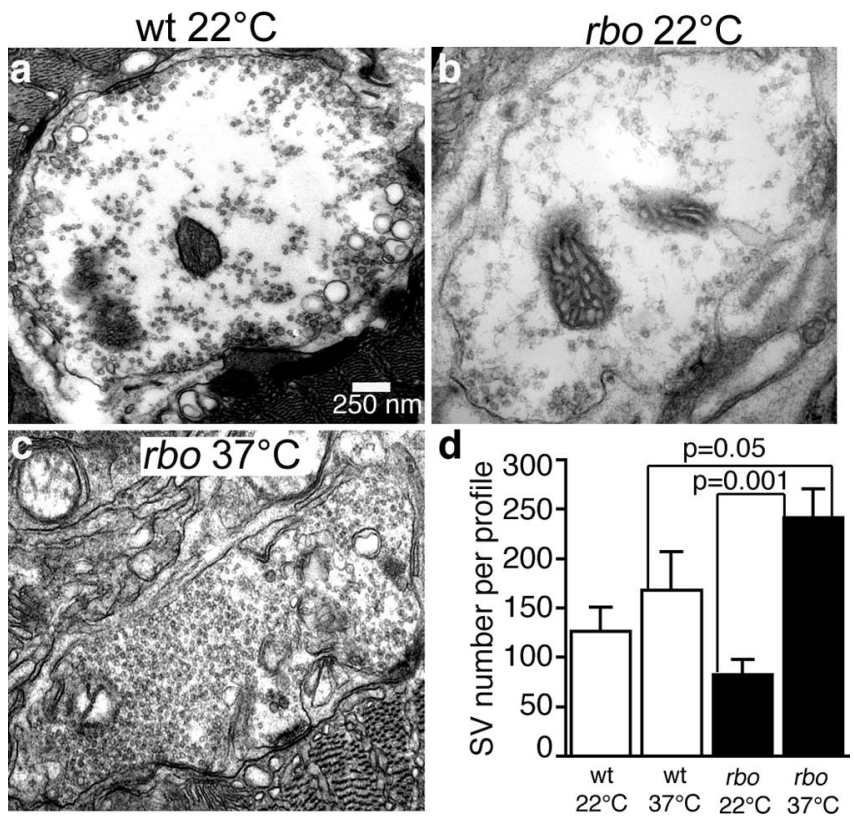

Figure 5. Conditional block of synaptic vesicle exocytosis in rbo mutants. $\boldsymbol{a}$, Representative electron micrograph of a DLM NMJ synaptic bouton from wt at room temperature $\left(22^{\circ} \mathrm{C}\right) \cdot \boldsymbol{b}$, Representative bouton of rbo mutant $\left(r b b^{t s} / / r b 0^{2}\right)$ at $22^{\circ} \mathrm{C}$. Note that SVs tend to be distributed toward active zones. $c$, Representative bouton of rbo mutant after a 10 min shift to $37^{\circ} \mathrm{C}$. Note dramatic increase in SV density. $\boldsymbol{d}$, Quantification of SV number per bouton profile. The bars show the mean \pm SEM.

shift to restrictive temperature $\left(37^{\circ} \mathrm{C}\right)$, in which $r b o^{t s l}$ mutants lack any detectable neurotransmission (Figs. 3,4 ).

At permissive temperature $\left(22^{\circ} \mathrm{C}\right)$, the ultrastructure of NMJ terminals in $r b o^{t s 1}$ mutants and wild-type controls appears essentially indistinguishable (Fig. 5). Both genotypes contain anatomically normal synaptic bouton profiles, active zones, and synaptic vesicles. The synaptic bouton area and the total number of SVs per bouton section are not significantly different $(p>0.05)$ in the two genotypes (Fig. 5). After a $10 \mathrm{~min}$ shift to $37^{\circ} \mathrm{C}$, the picture is very different. SV number in $r b o^{t s 1} / r b o^{2}$ mutants is almost tripled within 10 min (mean SV number per section: $82 \pm$ $16, n=22$ at $22^{\circ} \mathrm{C}$ vs $241 \pm 29, n=51$ at $37^{\circ} \mathrm{C} ; p=0.001$ ) (Fig. $5 c, d)$. At $37^{\circ} \mathrm{C}$, SV number in wild type is not changed significantly (Fig. $5 d$ ). The conditional increase in SV number is consistent with a block of exocytosis in $r b o^{t s 1}$ mutants. A similar increase in SV number has been reported in photoreceptor presynaptic terminals in comotase and syntaxin1A TS mutants with a SV exocytosis deficit (Kawasaki et al., 1998; Littleton et al., 1998) and the opposite defect of SV depletion in shibire TS mutant DLM NMJs with a block of SV endocytosis (Koenig et al., 1983). The SV accumulation in $r b o^{t s l}$ mutants suggests disruption in the balance between SV fusion and recycling from the plasma membrane, predicting a reduction in the presynaptic terminal membrane area. To test this prediction, NMJ boutons were visualized with anti-synaptotagmin (Fig. $2 c$ ) and bouton area quantified with confocal imaging. The temperature shift from 22 to $37^{\circ} \mathrm{C}$ resulted in a slight reduction of bouton area in $r b o$ mutants (from $0.99 \pm 0.02 \mu \mathrm{m}^{2}, n=224$ to $0.92 \pm 0.2 \mu \mathrm{m}^{2}, n=180$ ), but this change was not statistically significant. In EM studies, the largest sections from bouton serial sections containing at least one clearly define synaptic active zone were selected to quantify crosssectional area. After a $10 \mathrm{~min}$ shift to $37^{\circ} \mathrm{C}$, the cross-sectional bouton area in rbo mutants was reduced $\sim 38 \%\left(\mathrm{rbo}^{t s 1} / \mathrm{rbo}^{2}\right.$; $4.84 \pm 1.37 \mu \mathrm{m}^{2}, n=22$ at $22^{\circ} \mathrm{C}$ vs $2.98 \pm 0.5 \mu \mathrm{m}^{2}, p<0.05, n=$
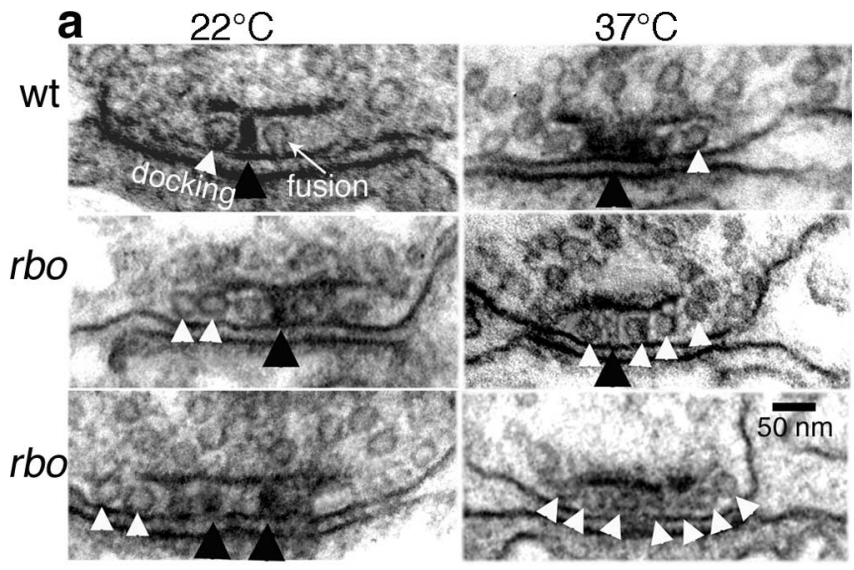

b

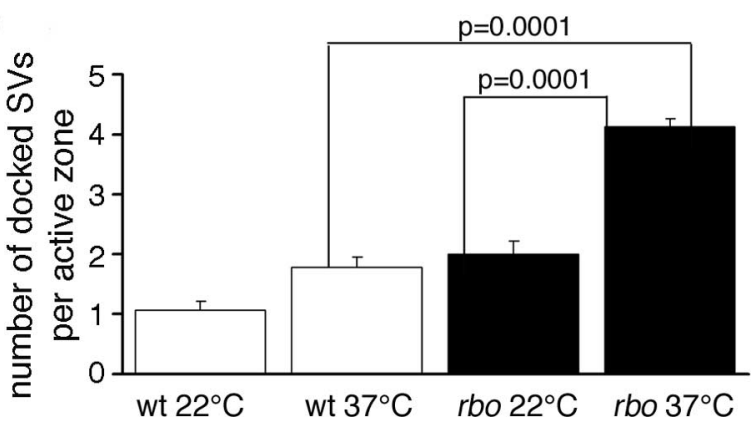

Figure 6. Docked synaptic vesicles arrest at the active zone in rbo mutants. $\boldsymbol{a}$, Representative electron micrographs of presynaptic AZ in wild type (top) and $r b o\left(r b 0^{t 51} / r b o^{2}\right.$ ) mutants (middle and bottom) at $22^{\circ} \mathrm{C}$ (left column) and after a $10 \mathrm{~min}$ shift to $37^{\circ} \mathrm{C}$ (right column). The electrondense AZ T-bar (black arrowheads) and morphologically docked SVs (white arrowheads) are indicated. $\boldsymbol{b}$, Quantification of the number of docked SVs per AZ. The bars show the mean \pm SEM.

51). The bouton area of wild-type controls shows no significant change during the same temperature shift. Together, these data support an acute and specific block in SV exocytosis in the absence of RBO function.

To determine the stage of the putative RBO-dependent SV exocytosis block, we next quantified SV density relative to the presynaptic AZ (Fig. 6). AZs in wild-type animals contain one or two SVs in contact (docked) with the electron-dense AZ membrane (Fig. $6 a$, arrowhead). The $r b o^{t s l}$ mutants at permissive temperature $\left(22^{\circ} \mathrm{C}\right)$ show a similar profile. In contrast, after $10 \mathrm{~min}$ shift to $37^{\circ} \mathrm{C}$, there is a significant accumulation of docked SVs in $r b o^{t s 1} / r b o^{2}$ mutants (SVs per AZ, $4.1 \pm 0.1$ ) when compared with both wild type at $37^{\circ} \mathrm{C}(1.8 \pm 0.14 ; p=0.0001)$ and with $r b o^{t_{s} 1} /$ $r b o^{2}$ mutants at $22^{\circ} \mathrm{C}(2.0 \pm 0.2 ; p=0.0001)$ (Fig. 6). Typically, all available electron-dense $\mathrm{AZ}$ membrane in the mutant appears occupied with docked SVs (Fig. 6a), suggesting that SV docking sites may be nearly or completely saturated. The accumulation of docked SVs is similar to that reported for comatose (DLM NMJs and photoreceptor synapses) and syntaxin (photoreceptor synapses) TS mutants with SV priming or fusion defects (Kawasaki et al., 1998; Littleton et al., 1998). This result further supports the existence of an exocytosis defect in $r b o^{t s l}$ mutants and suggests that $\mathrm{RBO}$ is required at a postdocking stage of SV exocytosis, during vesicle priming, or fusion stages.

SV priming is dependent on UNC-13, which can be recruited to plasma membrane by binding DAG (Brose and Rosenmund, 2002). We previously reported an acute, activity-dependent depletion of DAG in the brains of $r b o^{t s 1}$ mutants (Huang et al., 2004) and previously reported a dunc-13 docked SV accumula- 
tion phenotype very similar to the $r b o^{t s 1}$ phenotype reported here (Aravamudan et al., 1999). To test whether the block of SV exocytosis in $r b o^{t s 1}$ may correlate with mislocalization of dUNC-13, DLM synaptic boutons were stained with a dUNC-13 antibody and confocal imaging used to assay dUNC-13 expression (Fig. 7). The $r b o^{t s l}$ mutants at permissive temperature $\left(22^{\circ} \mathrm{C}\right)$ showed dUNC-13 expression indistinguishable from wild-type controls. After $10 \mathrm{~min}$ shift to $37^{\circ} \mathrm{C}$, there was no detect-

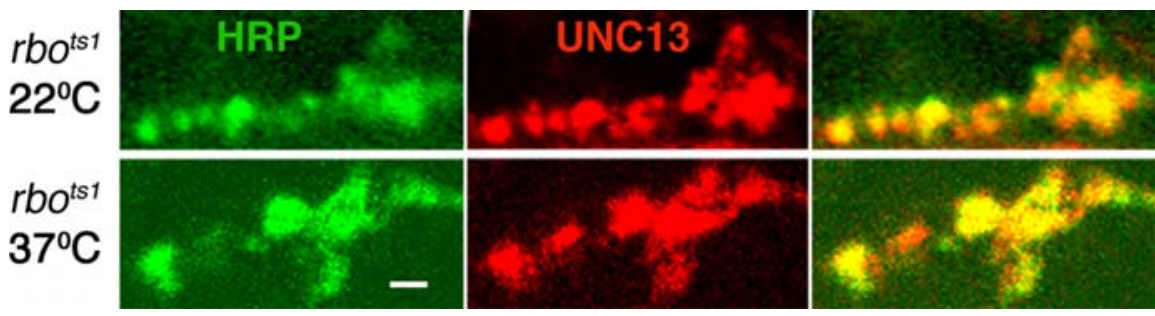

Figure 7. No detectable alteration of dUNC-13 distribution in rbo mutants. Adult DLM NMJ synaptic boutons double-labeled with anti-HRP (neuronal membrane; green) and an antibody to dUNC-13 (red) are shown. Representative images from $r b o\left(r b 0^{t 5} / / r b o^{2}\right.$ ) mutants at permissive temperature $\left(22^{\circ} \mathrm{C}\right.$, top) and after a $10 \mathrm{~min}$ shift to $37^{\circ} \mathrm{C}$ (bottom) are shown. Scale bar, $1.0 \mu \mathrm{m}$.

able change in either the expression inten-

sity or the bouton distribution of dUNC-13 (Fig. 7). This negative result might be because of the limited resolution of confocal imaging.

\section{RBO interacts with the syntaxin T-SNARE}

To investigate the molecular mechanism underlying the RBO requirement in synaptic transmission, we next generated double mutants of $r b o^{t s 1}$ and other Drosophila TS synaptic mutants. TS mutants tested in combination with rbo included the cacophony presynaptic $\mathrm{Ca}^{2+}$ channel ( cac $^{t s 2}$ ) (Dellinger et al., 2000), the syntaxin1A T-SNARE $\left(s y x^{3-69}\right)$ (Littleton et al., 1998), the comatose NSF ATPase $\left(\right.$ comt $^{t s 17}$, comt $\left.^{t 553}\right)$ (Siddiqi and Benzer, 1976), and the shibire dynamin GTPase (shibire ${ }^{t s l}$ ) (Grigliatti et al., 1973). To test for genetic interactions, behavioral paralysis was assayed at an intermediate temperature of $33^{\circ} \mathrm{C}$, at which $r b o$ single mutants (e.g., $r b o^{t s 1} / r b o^{t s 1}, r b o^{t s 1} / r b o^{2}$ ) are only slowly paralyzed over a time course of $\sim 30 \mathrm{~min}$. For the first $10 \mathrm{~min}$ at $33^{\circ} \mathrm{C}$, rbo homozygous mutants remain fully upright and mobile (Fig. $8 a$ ), thereby providing a sensitized condition in which to assay double homozygotes for accelerated paralysis. Under these conditions, rbo displays no obvious synergistic interaction with $\mathrm{ca}$ cophony, comatose, or shibire mutants (data not shown). In contrast, there is a strong synergistic interaction between $r b o^{t s l}$ and the $s y x^{3-69}$ mutation. To control for genetic background contributions, both $r b o^{t s 1} / r b o^{t s 1}$; sy $x^{3-69} / s y x^{3-69}$ and $r b o^{t s 1} / r b o^{2}$; sy $x^{3-69}$ / $s y x^{3-69}$ mutants were examined. Both types of double mutants showed an indistinguishable synergistic genetic interaction and are pooled together in Figure $8 a$.

After 10 min at $33^{\circ} \mathrm{C}$, sy $x^{3-69}$ homozygotes display only $\sim 10 \%$ paralysis. Paralyzed $s y x^{3-69}$ flies completely recover to an upright position within 1-2 min after return to room temperature. In contrast, $r b o^{t s 1} ; s y x^{3-69}$ double mutants rapidly paralyze at $33^{\circ} \mathrm{C}$, with $\sim 90 \%$ of mutants completely paralyzed within $10 \mathrm{~min}$ (Fig. $8 a$ ), and $\sim 5 \mathrm{~min}$ are required for all paralyzed $r b o^{t s 1} ; s y x^{3-69}$ double mutants to regain an upright position after return to room temperature (Fig. $8 b$ ). These observations suggest that $\mathrm{RBO}$ and syntaxin may act in the same pathway, or parallel pathways, required for neurotransmission.

\section{RBO may act downstream of SNARE complex assembly}

The $s y x^{3-69}$ allele is a missense mutation that causes temperaturedependent disruption of syntaxin 1A binding to SNAP25 and synaptobrevin, and hence a defect in the formation of SNARE complex (Littleton et al., 1998). Homozygous syx $x^{3-69}$ mutants display reduced SNARE complex formation at room temperature and no detectable SNARE complex formation after $20 \mathrm{~min}$ at $38^{\circ} \mathrm{C}$ (Littleton et al., 1998). Therefore, the synergistic genetic interaction between $r b o^{t s 1}$ and $s y x^{3-69}$ mutations in behavioral paralysis could be attributable to an additive negative effect on SNARE complex assembly or to a downstream syntaxin-dependent
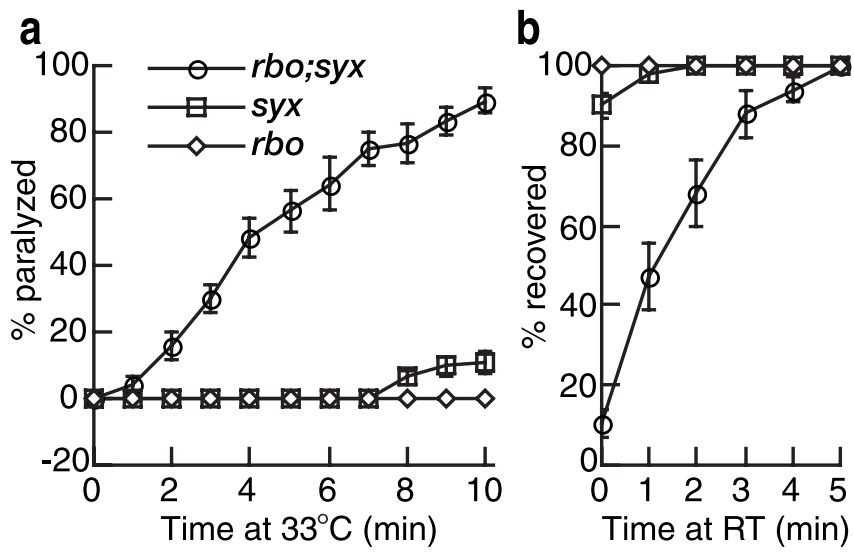

C
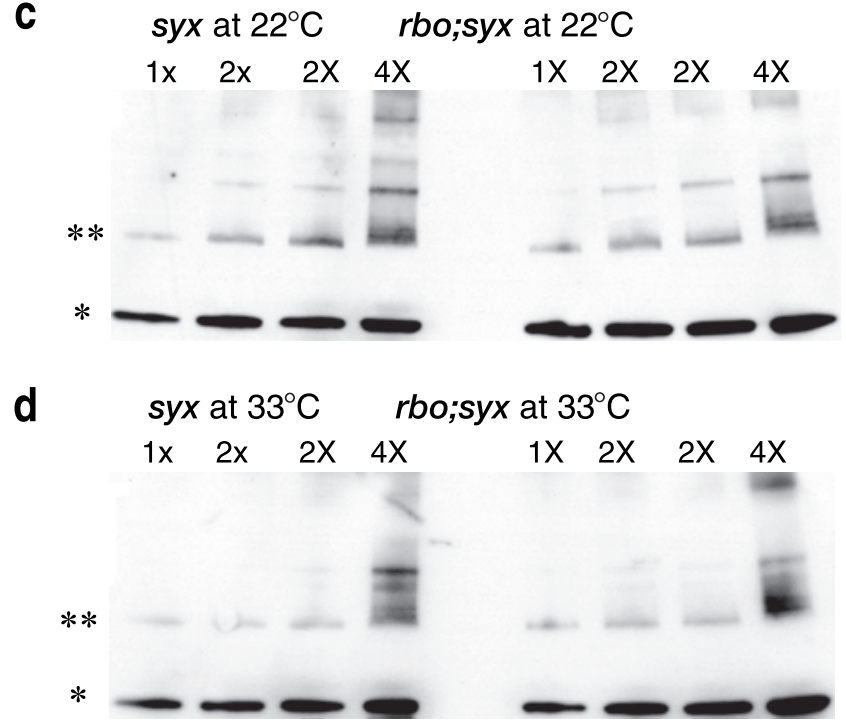

Figure 8. RBO genetically interacts with syntaxin. $\boldsymbol{a}, \boldsymbol{b}$, The kinetics of $\mathrm{TS}$ paralysis at $33^{\circ} \mathrm{C}(\boldsymbol{a})$ and recovery from paralysis at room temperature $\left(22^{\circ} \mathrm{C}\right)(\boldsymbol{b})$ in $r b 0\left(r b 0^{t 51} / \mathrm{rbo}^{2}\right.$ and $\left.r b 0^{t 51} / \mathrm{rbo} 0^{t 57}\right)$ and syx $\left(s y x^{3-69} / s y x^{3-69}\right)$ single mutants and $r b o ; s y x\left(r b 0^{t 51} / r b o^{2} ; s y x^{3-69} / s y x^{3-69}\right)$ double mutants. The rbo and syx mutants display a strong synergistic interaction. Error bars represent SEM. $\boldsymbol{c}, \boldsymbol{d}$, Representative anti-syntaxin1A Western blots of SNARE complex abundance in syx single mutants and $r b 0$; syx double mutants. Analyses at room temperature $\left(22^{\circ} \mathrm{C}\right)(\boldsymbol{c})$ and after a 10 min shift to $33^{\circ} \mathrm{C}(\boldsymbol{d})$ is shown. $1 \mathrm{x}, 2 \mathrm{x}$, and $4 \mathrm{x}$ indicate the loading amount of total plasma membrane protein determined by absorbance measurements at $280 \mathrm{~nm}$. Equal amount of total membrane protein from syx single mutants and rbo; syx double mutants were loaded. The bands indicated by ${ }^{*}$ and ${ }^{* *}$ represent syntaxin monomer and 7 S SNARE complex, respectively.

mechanism of SV fusion. To test these possibilities, we assayed the abundance of SNARE complex in sy $x^{3-69}$ mutants and $r b o^{t s 1}$ / $r b o^{2} ; s y x^{3-69} / s y x^{3-69}$ double mutants at both room temperature and $33^{\circ} \mathrm{C}$.

The ternary (7S) SNARE complex, composed of one molecule 
each of syntaxin, SNAP25, and synaptobrevin, is SDS resistant and migrates at $\sim 73 \mathrm{kDa}$ in SDS-PAGE (Littleton et al., 1998; Tolar and Pallanck, 1998). Equal amounts of total membrane proteins from brain extracts of both groups of mutants were subjected to SDS-PAGE and Western blot analyses with an antibody against syntaxin $1 \mathrm{~A}$ (8C3) (Fig. $8 c, d$ ). The 7S SNARE complex and syntaxin monomer abundance in $r b o^{t s 1} / r b o^{2} ; s y x^{3-69} /$ sy $x^{3-69}$ were normalized to $s y x^{3-69} / s y x^{3-69}$ of the same blot. At room temperature, double mutants contain $1.28 \pm 0.15(n=10)$ and $1.16 \pm 0.06(n=8)$ of 7 S SNARE and syntaxin 1 A monomers, respectively. After $10 \mathrm{~min}$ at $33^{\circ} \mathrm{C}$, normalized quantification shows that the double mutants still contain similar relative levels of 7S SNARE complex $(1.13 \pm 0.10 ; n=20)$ and syntaxin $1 \mathrm{~A}$ monomers $(1.23 \pm 0.07 ; n=19)$. Thus, no additive negative effect on SNARE complex assembly was detected in double mutants. We also compared SNARE complex abundance in $r b o^{t s 1} /$ $r b o^{2}$ and wild type (at 22 and $37^{\circ} \mathrm{C}$ ) and did not observe any significant difference between mutants and controls (data not shown). Together, these results suggest that the rbo defect in SV exocytosis likely occurs downstream of SNARE complex assembly.

\section{Discussion}

\section{RBO functions at a postdocking step in SV exocytosis}

$\mathrm{RBO}$ is a predicted integral plasma membrane lipase (Huang et al., 2004). The protein is highly enriched within the nervous system and is subcellularly restricted within central neurons primarily to synaptic domains. At neuromuscular synapses, RBO is predominantly localized to the plasma membrane within presynaptic boutons. The protein may also be present in the postsynaptic compartment, but we are currently unable to resolve this clearly at a confocal level. Conditional rbo mutants paralyze within minutes and display a complete block of synaptic transmission within minutes. This functional block correlates with a sharp increase in SV number within presynaptic boutons and a concomitant shrinkage of presynaptic plasma membrane area. These acute changes appear to arise from the disruption of the balance between SV consumption (exocytosis) and recycling by SV formation (endocytosis). Similar SV accumulation has been reported only in mutants with defective SV fusion, including comatose and syntaxin TS mutants (Kawasaki et al., 1998; Littleton et al., 1998). In rbo TS mutants, docked vesicles accumulate at presynaptic active zones within minutes. This defect is most consistent with a postdocking block of SV priming/fusion. However, because docking may be proportional to overall SV pool size (Weimer et al., 2003), the elevation in SV number might also contribute to the increased number of docked SVs.

Conditional TS paralytic mutations of rbo and syntaxin $1 \mathrm{~A}$ $\left(s y x^{3-69}\right)$ produce a strong synergistic genetic interaction. Among the pool of TS mutants tested, this interaction appears quite specific to syntaxin. Interactions were not observed between rbo and TS mutant affecting presynaptic $\mathrm{Ca}^{2+}$ influx, SNARE complex disassembly, or SV recycling. The rbo-syx interaction agrees well with the EM characterization indicating a requirement for RBO in postdocking SV exocytosis. The syx $x^{3-69}$ mutants display a temperature-dependent loss of SNARE complexes (Littleton et al., 1998). In $r b o^{t s 1} ; s y x^{3-69}$ double mutants, we found no further reduction of SNARE complex assembly. The assay included both trans- and cis-SNARE complexes, making it hard to correlate SNARE complex abundance with functional defects. Nevertheless, the absence of a discernable change in SNARE complex abundance in rbo mutants suggests that RBO is unlikely to function directly in SNARE assembly/disassembly. Together, these data therefore suggest that RBO likely acts either downstream of SNARE complex assembly or in an unknown parallel pathway leading to SV fusion.

The acute requirement for RBO protein appears to be limited to a subset of synapses; larval NMJ synapses do not show the same requirement. One possible explanation may be functional redundancy or differences in synaptic thermal regulation between larval and adult synapses. For unknown reasons, larva NMJ neurotransmission has proven consistently more resistant to disruption by Drosophila TS mutants than the adult (Suzuki et al., 1971; Siddiqi and Benzer, 1976). A second possibility is that RBO may be acutely required at synapses designed to function reliably under conditions of high demand. The central cholinergic and NMJ synapses in the adult Drosophila GF circuit can support $100 \mathrm{~Hz}$ synaptic transmission (Tanouye and Wyman, 1980; Engel and Wu, 1992; Allen et al., 2000), far beyond the usage or sustainable range of the larval NMJ.

\section{A role of $\mathrm{RBO}$ in SNARE-dependent synaptic vesicle fusion?}

It has been well demonstrated that SNARE complex assembly is essential for vesicle priming and can directly mediate membrane fusion (Weber et al., 1998; Jahn and Sudhof, 1999; Lin and Scheller, 2000; Sudhof, 2004). In addition, however, studies of yeast vacuolar homotypic fusion (Peters et al., 1999, 2001; Muller et al., 2002; Bayer et al., 2003) and direct studies of exocytosis of neurotransmitter vesicles including SVs (Ciufo et al., 2005; Hiesinger et al., 2005) suggest that an additional machinery may act downstream of the SNARE complex to mediate fusion. Our data suggest that RBO may similarly act downstream of SNARE complex assembly. We propose that RBO may regulate the function of the SV fusion machinery or may be a novel component of this fusion machinery.

The closest characterized homolog of $\mathrm{RBO}$ ( $42 \%$ conserved) is an integral plasma membrane sn-1 DAG lipase (Bisogno et al., 2003; Huang et al., 2004). We reported recently that RBO is essential for PLC-dependent neuronal signaling (Huang et al., 2004). Consistently, after a $10 \mathrm{~min}$ shift to $37^{\circ} \mathrm{C}$, rbo TS mutants display an accumulation of $\mathrm{PIP}_{2}$ and concomitant reduction of DAG in the brain (Huang et al., 2004). Synaptically localized $\mathrm{RBO}$ therefore may regulate the levels of fusogenic lipids (DAG, phosphatidylinositides, polyunsaturated fatty acids) at, or near, AZ fusion sites. These critical lipids may contribute directly to the generation of membrane properties required for SV fusion. Alternatively, these lipids might regulate the activity of lipidbinding fusogenic proteins.

Both lipid partitioning and protein interactions regulate membrane changes to enable fusion. Lipids with compact head groups and space-filling tails, such as $\mathrm{PIP}_{2}$ and DAG, favor the negative membrane curvature required for vesicle fusion, and both PIP 2 and DAG directly promote $\mathrm{Ca}^{2+}$-dependent exocytosis (Hay et al., 1995; Mayer et al., 2000; Di Paolo et al., 2004). Lipases including PLC, PLD, and PLA2 are known to promote secretion through the fusogenic effects of their lipid products (Cohen and Brown, 2001; Vitale et al., 2001; Brown et al., 2003; Wei et al., 2003; Staneva et al., 2004). These lipases have been proposed to increase presynaptic release site availability and/or vesicle fusion efficacy. These activities also coordinate the spatial-temporal regulation of numerous synaptic proteins (Wenk and De Camilli, 2004). SV priming is dependent on UNC-13, which binds DAG (Aravamudan et al., 1999). PIP 2 and DAG are required for the localized enrichment of SNARES and Rab GTPases at fusion sites (Jun et al., 2004). Other known targets of $\mathrm{PIP}_{2}$ and DAG include synaptotagmin 1 and MUNC18-interacting MINT1,2 (Cremona and De Camilli, 2001; Wenk and De Camilli, 
2004). Thus, phosphoinositides may play multiple roles in the formation of the SV fusion domain: directly determining membrane properties, serving as a precursor for other fusogenic lipids (DAG), and serving as anchors/regulators for fusogenic proteins.

Conditional removal of RBO activity in TS mutants causes acute DAG depletion and $\mathrm{PIP}_{2}$ accumulation in the brain (Huang et al., 2004). These changes correlate temporally with the loss of neurotransmission and the arrest of docked SVs at presynaptic AZs. We have yet to develop the technology to determine whether these lipid changes occur locally at the AZ, but the synaptic localization of $\mathrm{RBO}$ and the acute requirement of $\mathrm{RBO}$ in postdocking $\mathrm{SV}$ exocytosis supports this conclusion. Therefore, RBO is proposed to function as a presynaptic phospholipase that modulates the $\mathrm{PIP}_{2}-\mathrm{DAG}$ pathway to regulate SV fusion. Ongoing studies are aimed at determining the nature of this requirement and how $\mathrm{RBO}$ activity is regulated to control SV fusion efficacy and thereby neurotransmission strength.

\section{References}

Allen MJ, Shan X, Murphey RK (2000) A role for Drosophila Drac1 in neurite outgrowth and synaptogenesis in the giant fiber system. Mol Cell Neurosci 16:754-765.

Aravamudan B, Broadie K (2003) Synaptic Drosophila UNC-13 is regulated by antagonistic G-protein pathways via a proteosome-dependent degradation mechanism. J Neurobiol 54:417-438.

Aravamudan B, Fergestad T, Davis WS, Rodesch CK, Broadie K (1999) Drosophila UNC-13 is essential for synaptic transmission. Nat Neurosci 2:965-971.

Bayer MJ, Reese C, Buhler S, Peters C, Mayer A (2003) Vacuole membrane fusion: V0 functions after trans-SNARE pairing and is coupled to the $\mathrm{Ca}^{2+}$-releasing channel. J Cell Biol 162:211-222.

Bisogno T, Howell F, Williams G, Minassi A, Cascio MG, Ligresti A, Matias I, Schiano-Moriello A, Paul P, Williams EJ, Gangadharan U, Hobbs C, Di Marzo V, Doherty P (2003) Cloning of the first sn1-DAG lipases points to the spatial and temporal regulation of endocannabinoid signaling in the brain. J Cell Biol 163:463-468.

Broadie K (2000) Functional assays of the peripheral and central nervous systems. In: Drosophila protocols (Sullivan WAM, Hawley RS, eds), pp 297-312. New York: Cold Spring Harbor Laboratory.

Brose N, Rosenmund C (2002) Move over protein kinase C, you've got company: alternative cellular effectors of diacylglycerol and phorbol esters. J Cell Sci 115:4399-4411.

Brown WJ, Chambers K, Doody A (2003) Phospholipase A2 (PLA2) enzymes in membrane trafficking: mediators of membrane shape and function. Traffic 4:214-221.

Chandrashekaran S (1993) Mutations at the stm A locus of Drosophila melanogaster confer resistance to the sodium channel neuropoison veratridine. Curr Sci 65:80-82.

Ciufo LF, Barclay JW, Burgoyne RD, Morgan A (2005) Munc18-1 regulates early and late stages of exocytosis via syntaxin-independent protein interactions. Mol Biol Cell 16:470-482.

Cohen JS, Brown HA (2001) Phospholipases stimulate secretion in RBL mast cells. Biochemistry 40:6589-6597.

Cremona O, De Camilli P (2001) Phosphoinositides in membrane traffic at the synapse. J Cell Sci 114:1041-1052.

Dellinger B, Felling R, Ordway RW (2000) Genetic modifiers of the Drosophila NSF mutant, comatose, include a temperature-sensitive paralytic allele of the calcium channel alphal-subunit gene, cacophony. Genetics 155:203-211.

Di Paolo G, Moskowitz HS, Gipson K, Wenk MR, Voronov S, Obayashi M, Flavell R, Fitzsimonds RM, Ryan TA, De Camilli P (2004) Impaired PtdIns $(4,5) \mathrm{P} 2$ synthesis in nerve terminals produces defects in synaptic vesicle trafficking. Nature 431:415-422.

Engel JE, Wu CF (1992) Interactions of membrane excitability mutations affecting potassium and sodium currents in the flight and giant fiber escape systems of Drosophila. J Comp Physiol A Neuroethol Sens Neural Behav Physiol 171:93-104.

Fergestad T, Broadie K (2001) Interaction of stoned and synaptotagmin in synaptic vesicle endocytosis. J Neurosci 21:1218-1227.

Fratti RA, Jun Y, Merz AJ, Margolis N, Wickner W (2004) Interdependent assembly of specific regulatory lipids and membrane fusion proteins into the vertex ring domain of docked vacuoles. J Cell Biol 167:1087-1098.

Goni FM, Alonso A (1999) Structure and functional properties of diacylglycerols in membranes. Prog Lipid Res 38:1-48.

Grigliatti TA, Hall L, Rosenbluth R, Suzuki DT (1973) Temperaturesensitive mutations in Drosophila melanogaster. XIV. A selection of immobile adults. Mol Gen Genet 120:107-114.

Hardie RC (2003) Regulation of trp channels via lipid second messengers. Annu Rev Physiol 65:735-759.

Hay JC, Fisette PL, Jenkins GH, Fukami K, Takenawa T, Anderson RA, Martin TF (1995) ATP-dependent inositide phosphorylation required for $\mathrm{Ca}^{2+}$-activated secretion. Nature 374:173-177.

Hiesinger PR, Fayyazuddin A, Mehta SQ, Rosenmund T, Schulze KL, Zhai RG, Verstreken P, Cao Y, Zhou Y, Kunz J, Bellen HJ (2005) The v-ATPase V0 subunit a1 is required for a late step in synaptic vesicle exocytosis in Drosophila. Cell 121:607-620.

Huang FD, Matthies HJ, Speese SD, Smith MA, Broadie K (2004) Rolling blackout, a newly identified PIP2-DAG pathway lipase required for Drosophila phototransduction. Nat Neurosci 7:1070-1078.

Ikeda K, Koenig JH (1988) Morphological identification of the motor neurons innervating the dorsal longitudinal flight muscle of Drosophila melanogaster. J Comp Neurol 273:436-444.

Jackson FR, Wilson SD, Hall LM (1986) The tip-E mutation of Drosophila decreases saxitoxin binding and interacts with other mutations affecting nerve membrane excitability. J Neurogenet 3:1-17.

Jahn R, SudhofTC (1999) Membrane fusion and exocytosis. Annu Rev Biochem 68:863-911.

Jun Y, Fratti RA, Wickner W (2004) Diacylglycerol and its formation by phospholipase $\mathrm{C}$ regulate Rab- and SNARE-dependent yeast vacuole fusion. J Biol Chem 279:53186-53195.

Kawasaki F, Ordway RW (1999) The Drosophila NSF protein, dNSF1, plays a similar role at neuromuscular and some central synapses. J Neurophysiol 82:123-130.

Kawasaki F, Mattiuz AM, Ordway RW (1998) Synaptic physiology and ultrastructure in comatose mutants define an in vivo role for NSF in neurotransmitter release. J Neurosci 18:10241-10249.

Kawasaki F, Felling R, Ordway RW (2000) A temperature-sensitive paralytic mutant defines a primary synaptic calcium channel in Drosophila. J Neurosci 20:4885-4889.

Kidokoro Y, Kuromi H, Delgado R, Maureira C, Oliva C, Labarca P (2004) Synaptic vesicle pools and plasticity of synaptic transmission at the Drosophila synapse. Brain Res Brain Res Rev 47:18-32.

King DG, Wyman RJ (1980) Anatomy of the giant fibre pathway in Drosophila. I. Three thoracic components of the pathway. J Neurocytol 9:753-770

Koenig JH, Ikeda K (1996) Synaptic vesicles have two distinct recycling pathways. J Cell Biol 135:797-808.

Koenig JH, Saito K, Ikeda K (1983) Reversible control of synaptic transmission in a single gene mutant of Drosophila melanogaster. J Cell Biol 96:1517-1522.

Lin RC, Scheller RH (2000) Mechanisms of synaptic vesicle exocytosis. Annu Rev Cell Dev Biol 16:19-49.

Littleton JT, Chapman ER, Kreber R, Garment MB, Carlson SD, Ganetzky B (1998) Temperature-sensitive paralytic mutations demonstrate that synaptic exocytosis requires SNARE complex assembly and disassembly. Neuron 21:401-413.

Loughney K, Kreber R, Ganetzky B (1989) Molecular analysis of the para locus, a sodium channel gene in Drosophila. Cell 58:1143-1154.

Martin TF (2001) PI(4,5) P(2) regulation of surface membrane traffic. Curr Opin Cell Biol 13:493-499.

Mayer A, Scheglmann D, Dove S, Glatz A, Wickner W, Haas A (2000) Phosphatidylinositol 4,5-bisphosphate regulates two steps of homotypic vacuole fusion. Mol Biol Cell 11:807-817.

Muller O, Bayer MJ, Peters C, Andersen JS, Mann M, Mayer A (2002) The Vtc proteins in vacuole fusion: coupling NSF activity to $\mathrm{V}(0)$ transcomplex formation. EMBO J 21:259-269.

Ordway RW, Pallanck L, Ganetzky B (1994) Neurally expressed Drosophila genes encoding homologs of the NSF and SNAP secretory proteins. Proc Natl Acad Sci USA 91:5715-5719.

Pavlidis P, Tanouye MA (1995) Seizures and failures in the giant fiber pathway of Drosophila bang-sensitive paralytic mutants. J Neurosci 15:5810-5819. 
Peters C, Andrews PD, Stark MJ, Cesaro-Tadic S, Glatz A, Podtelejnikov A, Mann M, Mayer A (1999) Control of the terminal step of intracellular membrane fusion by protein phosphatase 1. Science 285:1084-1087.

Peters C, Bayer MJ, Buhler S, Andersen JS, Mann M, Mayer A (2001) Transcomplex formation by proteolipid channels in the terminal phase of membrane fusion. Nature 409:581-588.

Rao SS, Stewart BA, Rivlin PK, Vilinsky I, Watson BO, Lang C, Boulianne G, Salpeter MM, Deitcher DL (2001) Two distinct effects on neurotransmission in a temperature-sensitive SNAP-25 mutant. EMBO J 20:6761-6771.

Ritchie JM (1979) A pharmacological approach to the structure of sodium channels in myelinated axons. Annu Rev Neurosci 2:341-362.

Rohrbough J, Broadie K (2005) Lipid regulation of the synaptic vesicle cycle. Nat Rev Neurosci 6:139-150.

Siddiqi O, Benzer S (1976) Neurophysiological defects in temperaturesensitive paralytic mutants of Drosophila melanogaster. Proc Natl Acad Sci USA 73:3253-3257.

Staneva G, Angelova MI, Koumanov K (2004) Phospholipase A2 promotes raft budding and fission from giant liposomes. Chem Phys Lipids 129:53-62.

Sudhof TC (2004) The synaptic vesicle cycle. Annu Rev Neurosci 27:509-547.

Suzuki DT, Grigliatti T, Williamson R (1971) Temperature-sensitive mutations in Drosophila melanogaster. VII. A mutation (para-ts) causing reversible adult paralysis. Proc Natl Acad Sci USA 68:890-893.

Suzuki N, Wu CF (1984) Altered sensitivity to sodium channel-specific neurotoxins in cultured neurons from temperature-sensitive paralytic mutants of Drosophila. J Neurogenet 1:225-238.

Tanouye MA, Wyman RJ (1980) Motor outputs of giant nerve fiber in Drosophila. J Neurophysiol 44:405-421.

Tolar LA, Pallanck L (1998) NSF function in neurotransmitter release involves rearrangement of the SNARE complex downstream of synaptic vesicle docking. J Neurosci 18:10250-10256.
Trimarchi JR, Murphey RK (1997) The shaking-B2 mutation disrupts electrical synapses in a flight circuit in adult Drosophila. J Neurosci 17:4700-4710.

Tucker WC, Weber T, Chapman ER (2004) Reconstitution of $\mathrm{Ca}^{2+}$ regulated membrane fusion by synaptotagmin and SNAREs. Science 304:435-438.

van der Bliek AM, Meyerowitz EM (1991) Dynamin-like protein encoded by the Drosophila shibire gene associated with vesicular traffic. Nature 351:411-414.

Vijayakrishnan N, Broadie K (2006) Temperature-sensitive paralytic mutants: insights into the synaptic vesicle cycle. Biochem Soc Trans 34:81-7.

Vitale N, Caumont AS, Chasserot-Golaz S, Du G, Wu S, Sciorra VA, Morris AJ, Frohman MA, Bader MF (2001) Phospholipase D1: a key factor for the exocytotic machinery in neuroendocrine cells. EMBO J 20:2424-2434.

Weber T, Zemelman BV, McNew JA, Westermann B, Gmachl M, Parlati F, Sollner TH, Rothman JE (1998) SNAREpins: minimal machinery for membrane fusion. Cell 92:759-772.

Wei S, Ong WY, Thwin MM, Fong CW, Farooqui AA, Gopalakrishnakone P, Hong W (2003) Group IIA secretory phospholipase A2 stimulates exocytosis and neurotransmitter release in pheochromocytoma-12 cells and cultured rat hippocampal neurons. Neuroscience 121:891-898.

Weimer RM, Richmond JE, Davis WS, Hadwiger G, Nonet ML, Jorgensen EM (2003) Defects in synaptic vesicle docking in unc-18 mutants. Nat Neurosci 6:1023-1030.

Wenk MR, De Camilli P (2004) Protein-lipid interactions and phosphoinositide metabolism in membrane traffic: insights from vesicle recycling in nerve terminals. Proc Natl Acad Sci USA 101:8262-8269.

Wu CF, Ganetzky B (1980) Genetic alteration of nerve membrane excitability in temperature-sensitive paralytic mutants of Drosophila melanogaster. Nature 286:814-816. 